(C) 2007 The Japan Society of Applied Physics

\title{
Magnesium Doping of In-rich InGaN
}

\author{
Chin-An Chang, Tzu-Yu Tang, Pen-Hsiu Chang*, Nie-Chuan Chen, and Chi-Te Liang ${ }^{1}$ \\ Department of Electronic Engineering, Chang Gung University, Tao-Yuan, Taiwan, Republic of China \\ ${ }^{1}$ Department of Physics, National Taiwan University, Taipei, Taiwan, Republic of China
}

(Received September 8, 2006; revised January 4, 2007; accepted January 30, 2007; published online May 8, 2007)

InN and In-rich InGaN were grown by metal organic vapor phase epitaxy with magnesium doping. A set of samples were grown at $550^{\circ} \mathrm{C}$, whereas a second set of samples were grown at increasing temperature with Ga content. Upon annealing, pInGaN was obtained from the second set up to an In content above 50\%, with an acceptor concentration of $\sim 1 \times 10^{19} \mathrm{~cm}^{-3}$ and a mobility of $1-2 \mathrm{~cm}^{2} \mathrm{~V}^{-1} \mathrm{~s}^{-1}$. None of the samples grown at a constant temperature of $550{ }^{\circ} \mathrm{C}$ showed a p-behavior after heat treatment. The electrical, optical, structural and morphological characteristics of the films grown were analyzed, and the leveling off of hole concentration beyond an In content of 30\% was consistent with the reported decreasing activation energy of $\mathrm{Mg}$ with increasing In content. [DOI: 10.1143/JJAP.46.2840]

KEYWORDS: InN, In-rich InGaN, metal organic vapor phase epitaxy, magnesium doping, p-InGaN

\section{Introduction}

Research on InN and In-rich InGaN has been intensive in recent years awing to the narrow band gap of $\mathrm{InN} .{ }^{1-3)}$ The possible realization of nitride optoelectronic devices up to a wavelength of $1.6 \mu \mathrm{m}$ has prompted a wide interest in such materials. However, the technical challenges is the growth of p-InGaN with high In content. Kumakura et al. reported a correlation between the activation energy of $\mathrm{Mg}$ and the measured hole concentrations in the InGaN films up to an In content of $13 \% .^{4)}$ An increase in In content was accompanied by both an increase in hole concentration and a decrease in the activation energy of magnesium. A recent report has extended the $\mathrm{Mg}$-doping to $\mathrm{InGaN}$ with an In content of $40 \%{ }^{5)}$ In this paper we report the growth of $\mathrm{Mg}$ doped InGaN with different In contents using both fixed and varying growth temperatures. The samples grown at elevated temperatures showed a p-behavior upon annealing up to an In content above $50 \%$, likely the highest value being reported.

\section{Experimental Procedure}

InGaN films with different In contents were grown on (0001) sapphire substrates by metal organic vapor phase epitaxy (MOVPE) in an Aixtron 200/4 RF-S reactor. A $20 \mathrm{~nm} \mathrm{GaN}$ nucleation layer was first deposited at $500^{\circ} \mathrm{C}$, followed by a $2 \mu \mathrm{m} \mathrm{GaN}$ layer grown at $1000^{\circ} \mathrm{C}$. Thereafter, a 200-300 nm Mg-doped InGaN layer was grown by one of the following two methods. A constant growth temperature of $550^{\circ} \mathrm{C}$ was used for the first set of samples, and elevated temperatures were used for the second set of samples, as shown in Table I. The compositions indicated were for the intended growth based on the growth rates of InN and GaN. A comparison with the actual compositions shown later helped evaluate the effect of the preferential evaporation of $\mathrm{InN}$ at different temperatures. The purpose of designing two sets of growth conditions was to prevent the preferential evaporation of InN during the growth of an alloy of $\mathrm{InN}$ and $\mathrm{GaN}$ at elevated temperatures. It also allowed a correlation between the film properties and growth temperatures for the individual compositions. The metalorganic precursors used were triethylgallium (TEG) for Ga, trimethylindium (TMI)

*E-mail address: phchang@mail.cgu.edu.tw
Table I. In contents of samples grown at different temperatures.

\begin{tabular}{lcccccc}
\hline \multicolumn{1}{c}{$x$ of $\mathrm{In}_{x} \mathrm{Ga}_{1-x} \mathrm{~N}$} & 1 & 0.8 & 0.6 & 0.4 & 0.2 & 0 \\
\hline Sample number & $\mathrm{A}$ & $\mathrm{B}$ & $\mathrm{C}$ & $\mathrm{D}$ & $\mathrm{E}$ & - \\
Growth temp. $\left({ }^{\circ} \mathrm{C}\right)$ & 550 & 550 & 550 & 550 & 550 & - \\
Sample number & - & $\mathrm{b}$ & $\mathrm{c}$ & $\mathrm{d}$ & $\mathrm{e}$ & $\mathrm{f}$ \\
Growth temp. $\left({ }^{\circ} \mathrm{C}\right)$ & - & 600 & 650 & 700 & 750 & 900 \\
\hline
\end{tabular}

for In, and $\mathrm{NH}_{3}$ for nitrogen, all with nitrogen carrier gases. Biscyclopentadienyl magnesium $(\mathrm{Cp} 2 \mathrm{Mg}$ ) was used for $\mathrm{Mg}$ doping. The typical flow rates used were $400 \mathrm{sccm}$ for TMI, varying rates for TEG, $18,000 \mathrm{sccm}$ for $\mathrm{NH}_{3}$, and $8 \times 10^{-7}$ $\mathrm{mole} / \mathrm{min}$ for $\mathrm{Cp} 2 \mathrm{Mg}$. Both sets of $\mathrm{InGaN}$ layers were annealed at 600,650 and $700{ }^{\circ} \mathrm{C}$ in a nitrogen ambient to activate the doped magnesium. The films were analyzed by Hall measurement, photoluminescence (PL), X-ray diffraction (XRD), atomic force microscopy (AFM), and scanning electron microscopy (SEM).

\section{Results and Discussion}

As shown by electrical measurement later, $\mathrm{p}-\mathrm{InGaN}$ was achieved only for the second set of samples grown at elevated temperatures. Therefore, we concentrate on the characterization of this set of samples and compare this set with the first set when needed. A detailed comparison between the two sets of samples will be reported at a later date. The compositions of the InGaN films were determined by X-ray diffraction analysis, as shown in Fig. 1. Using Vegard's law, the determined compositions were labeled in the insets in the figures. Except for the samples intended for an In content of $80 \%$, all the InGaN samples grown at temperatures higher than $550{ }^{\circ} \mathrm{C}$ showed a lower In content than those grown at $550^{\circ} \mathrm{C}$. This is attributed to the high evaporation rate of $\mathrm{InN}$ at elevated temperatures. Similar results were reported by Yoshimoto et al. ${ }^{6)}$ As shown below for both sets of InGaN, the deviation between the intended and actual compositions correlated with both the growth temperatures and contents of In and Ga in the InGaN grown. The deviation was small toward the In-rich end; however, it was large toward the Ga-rich end. In addition, all the $\mathrm{InGaN}$ layers grown at $550{ }^{\circ} \mathrm{C}$ showed a narrower full-width at halfmaximum (FWHM) than those grown at temperatures higher than $550{ }^{\circ} \mathrm{C}$. The most possible reason will be discussed 


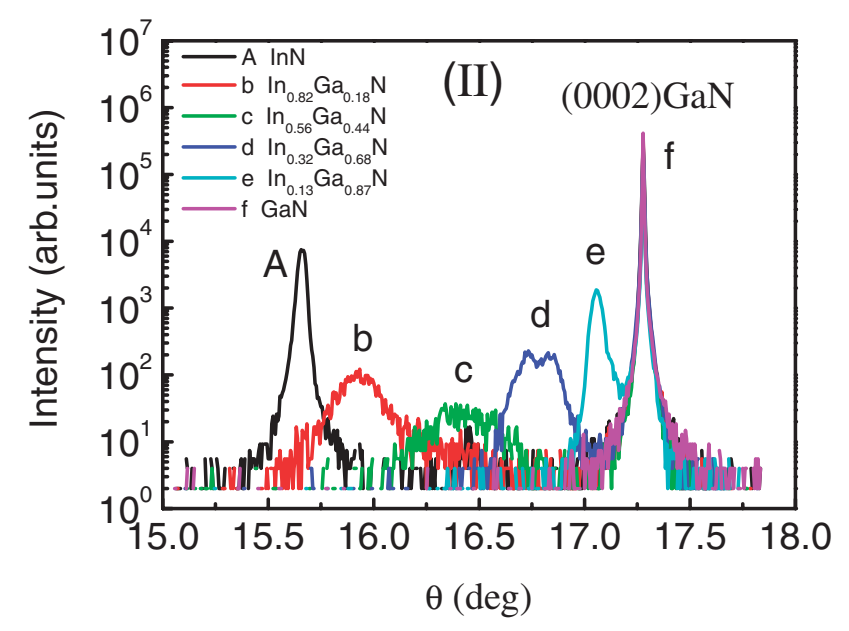

Fig. 1. X-ray diffraction patterns of second set (II) of InGaN grown at different temperatures. The growth temperatures used were 550, 600, 650, 700,750 , and $900^{\circ} \mathrm{C}$ for the samples $\mathrm{A}, \mathrm{b}, \mathrm{c}, \mathrm{d}, \mathrm{e}$, and f, respectively.

later. Within each set of InGaN samples, the FWHM increased toward the $\mathrm{In}_{0.5} \mathrm{Ga}_{0.5} \mathrm{~N}$ region. The FWHM values measured were $118,258,540,252$, and 160 arcsec for the samples grown at $550^{\circ} \mathrm{C}$ with the In contents of 100,79 , 57, 36, and 19\%, respectively. For the samples grown at elevated temperatures, the FWHM values were 538, 1014, 756,154 , and $15 \operatorname{arcsec}$ for the InGaN films with the In contents of $82,56,32,13$, and $0 \%$, respectively. This is consistent with the pattern of non uniformity in the alloy growth.

The PL measurement of the InGaN films showed the progressive shifts of emission wavelength from about $1.7 \mu \mathrm{m}$ to $361 \mathrm{~nm}$ for both sets of samples. The PL spectra measured at $10 \mathrm{~K}$ are shown in Fig. 2 for the second set of samples. The long-wavelength emission of $\mathrm{InN}$ reported by many groups $^{7-13)}$ was again confirmed here. The FWHM varied from sample to sample and was also affected by the growth temperatures used. The AFM analysis of the surface morphology indicated a progressively smoother surface toward the Ga-rich end of the InGaN films grown. This was observed for both sets of samples.

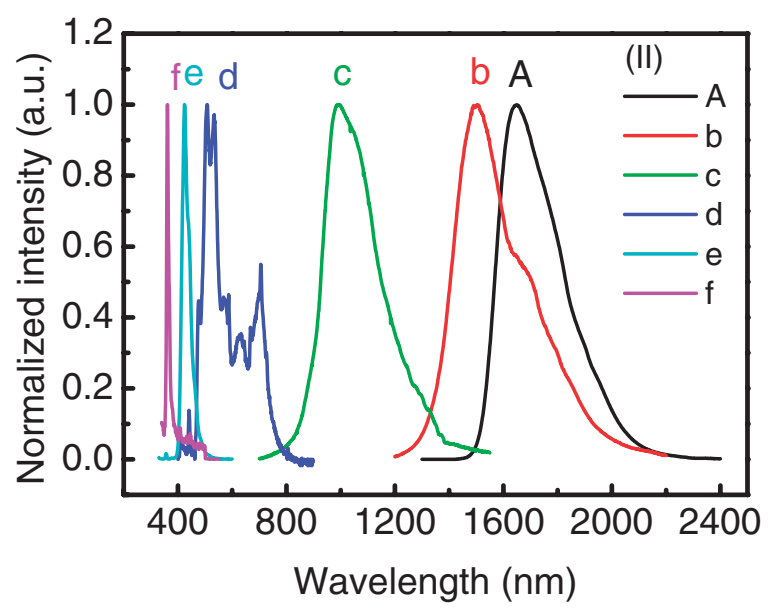

Fig. 2. PL spectra of second set (II) of InGaN grown at different temperatures. The growth temperatures were $600,650,700,750$, and $900{ }^{\circ} \mathrm{C}$ for the samples $\mathrm{b}, \mathrm{c}, \mathrm{d}, \mathrm{e}$, and $\mathrm{f}$, respectively.
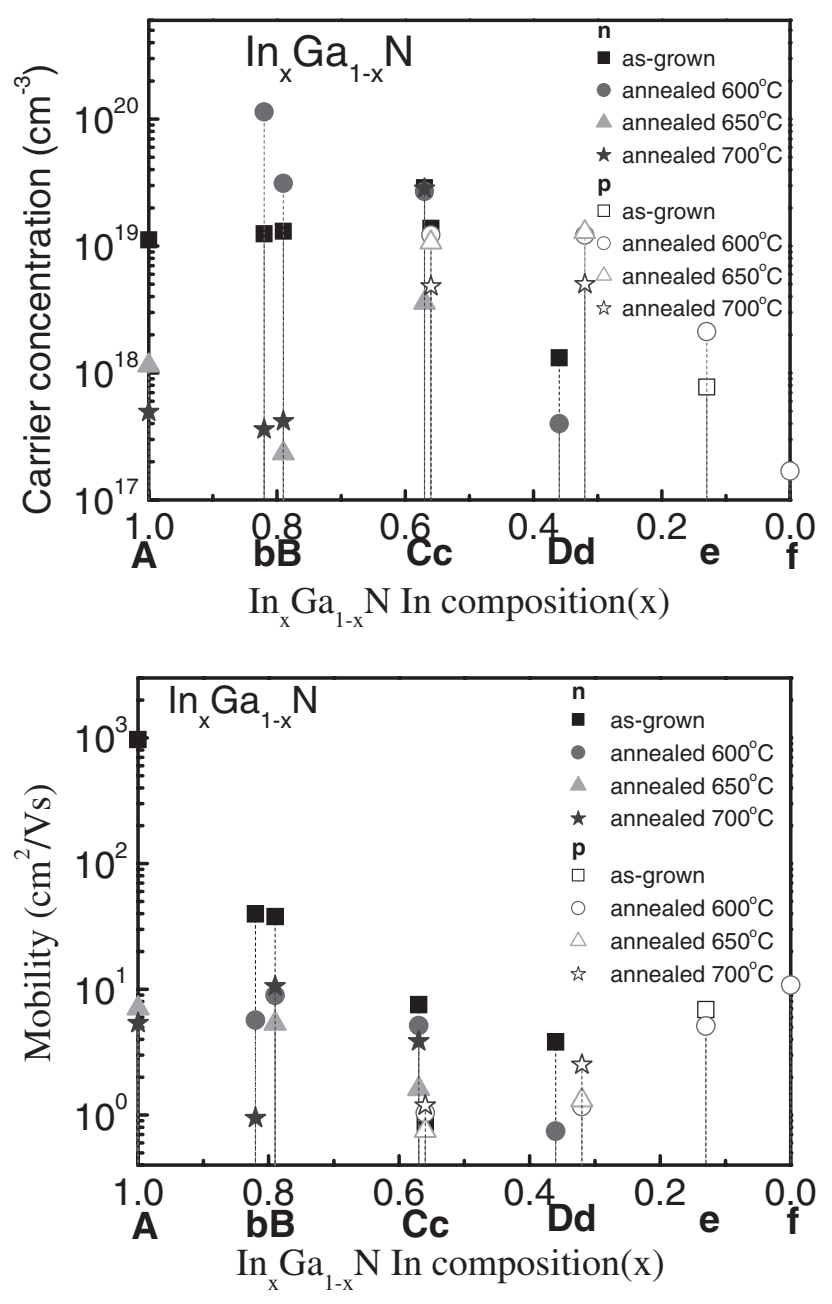

Fig. 3. Electrical measurement of two sets of InGaN grown at different temperatures and annealed. Upper: carrier concentration as function of In content of InGaN films. Lower: carrier mobility as function of In content of InGaN films.

The electric measurement showed an interesting result for the samples grown at different temperatures. Each set went through the same annealing. Annealing was performed at $600,650,700{ }^{\circ} \mathrm{C}$ for $30 \mathrm{~min}$ in $\mathrm{N}_{2}$ atmosphere. All the samples grown at $550^{\circ} \mathrm{C}$ were n-type before and after annealing. Using elevated growth temperatures, p-type InGaN was achieved after annealing up to an In content of $56 \%$. This was likely the highest In content reported for pInGaN. The measured carrier concentration and mobility are summarized in Fig. 3 for both sets of samples. The hole concentrations were in the range of $(5-10) \times 10^{18} \mathrm{~cm}^{-3}$, with a hole mobility of $1-2 \mathrm{~cm}^{2} \mathrm{~V}^{-1} \mathrm{~s}^{-1}$. In addition, as previously mentioned, Fig. 3 clearly shows a correlation of the deviation between the intended and actual compositions with the growth temperatures and In contents used. The increasing deviation noted for the second set of samples toward the Ga-rich end was consistent with the preferential evaporation of InN at high temperatures. The annealing at increasing temperatures caused a large reduction in both the electron concentration and mobility for both $\mathrm{InN}$ and In-rich InGaN films. This is related to the accompanied changes in film thickness at elevated temperatures. One example is shown in Fig. 4 for sample d. The thickness of 


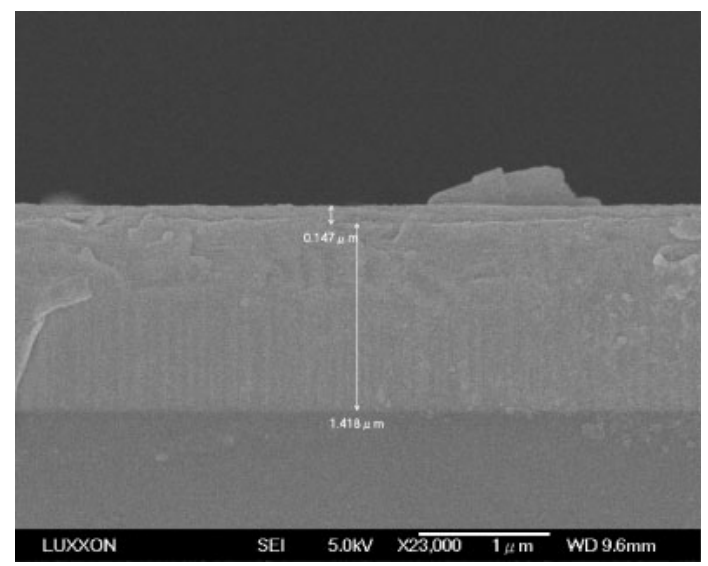

(a)

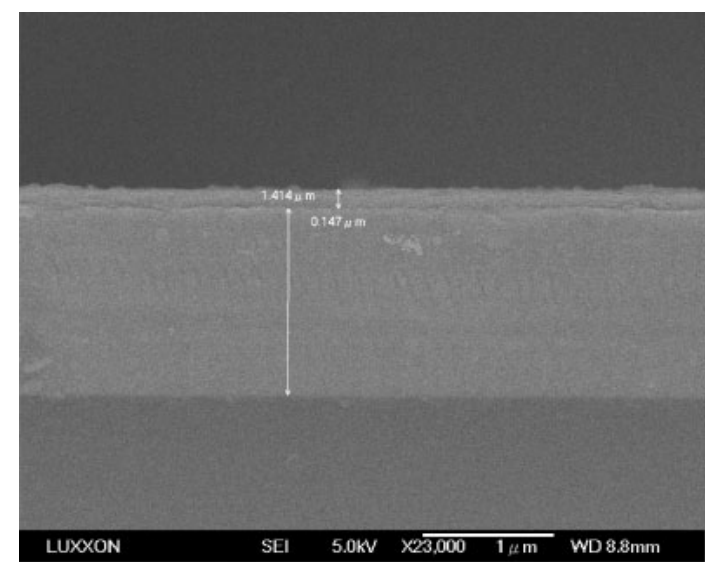

(b)

Fig. 4. Cross-sectional scanning electron micrographs of sample d annealed at (a) 650 and (b) $700{ }^{\circ} \mathrm{C}$, showing reduced thickness for (b).

the $\mathrm{In}_{0.32} \mathrm{Ga}_{0.68} \mathrm{~N}$ layer changed from 188 to $147 \mathrm{~nm}$ after annealing at 650 and $700{ }^{\circ} \mathrm{C}$.

The hole concentrations of both $\operatorname{In}_{0.32} \mathrm{Ga}_{0.68} \mathrm{~N}$ and $\mathrm{In}_{0.56} \mathrm{Ga}_{0.44} \mathrm{~N}$ were much higher than that of $3 \times 10^{17} \mathrm{~cm}^{-3}$ for the Mg-doped $\mathrm{GaN}$. The flow rates used for the various precursors of $\mathrm{Mg}$, In, and $\mathrm{Ga}$, as previously described, indicated a $\mathrm{Cp}_{2} \mathrm{Mg} / \mathrm{III}$ ratio of $\sim(1-4) \times 10^{-3}$, which corresponds to a $\mathrm{Mg}$ incorporation of about $10^{19} \mathrm{~cm}^{-3}$. By the Hall measurement of the $\mathrm{p}$-InGaN grown, an activation rate of about $10 \%$ was estimated for $\mathrm{Mg}$ in these InGaN films. This is consistent with the analysis of Kumakura, Makimoto, and Kobayashi $(\mathrm{KMK})^{4)}$ These authors showed that the activation energy of $\mathrm{Mg}$ in $\mathrm{InGaN}$ decreases with increasing In content up to $13 \%$, with a simultaneous increase in measured acceptor concentration. Figure 5 shows our data on the hole concentration as a function of the In content of the InGaN grown. Also added in the figure are the results of KMK that correlate well with the current results. The concentration seemed to level off at an In content above $30 \%$. An interesting correlation might exist between such an observation and the reducing activation energy of $\mathrm{Mg}$ as reported by KMK. The extrapolation of the latter work

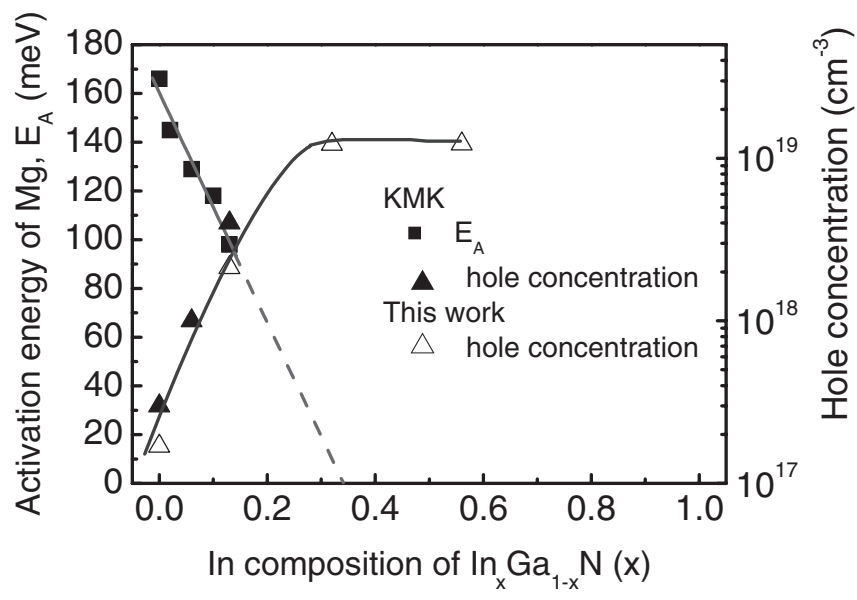

Fig. 5. Hole concentration of InGaN films as function of In content. Also included are the hole concentration reported by KMK and the activation energy of the $\mathrm{Mg}$ acceptor in InGaN (ref. 3). seemed to indicate a decrease in the activation energy of $\mathrm{Mg}$ at an In content of around $30 \%$. This would be favorable to the growth of high-concentration, p-type In-rich InGaN for both contact and device applications. Whether the analogy described is a mere coincidence is worthy of further investigation.

The growth of magnesium-doped, p-type In-rich InGaN faced the challenge of compensating a high background donor concentration. Our study has shown a clear role of the growth temperatures of InGaN. None of the samples grown at $550{ }^{\circ} \mathrm{C}$ showed a p-InGaN after annealing. Only those grown at elevated temperatures showed p-behavior after annealing up to an In content above 50\%. Apparently, the growth at a higher temperature benefited the incorporation of $\mathrm{Mg}$ into a favorable site for the subsequent activation to occur. Such growth should also improve the quality of InGaN that, in turn, contributes to the activation process considered. One puzzling fact is the FWHM values of the samples grown at increasing temperatures are larger than those of the samples grown at $550{ }^{\circ} \mathrm{C}$. Whether the larger FWHM values of the former are partly due to the presence of phase separation requires the detailed analysis of the PL spectra. Our earlier study on the In-rich InGaN showed a phase separation at an In content of around 80\%. ${ }^{10)}$ A low growth temperature would normally hinder the migration of the adsorbed In and Ga, preventing the best lattice arrangement required for the phase separation to grown at a constant temperature of $550^{\circ} \mathrm{C}$. In addition, the growth at such a temperature would also generate films with an inferior quality, which is unfavorable to the activation of $\mathrm{Mg}$. In this regard, annealing at temperatures higher than those reported here might shed light to this issue provided that the thermal decomposition of InGaN could be avoided.

\section{Conclusions}

In summary, Mg-doped InGaN films with different compositions were grown at both constant and elevated temperatures. The effects of growth temperatures on the actual compositions obtained were correlated with the preferential evaporation of $\mathrm{InN}$, which became increasingly larger toward the Ga-rich end. P-type $\mathrm{InGaN}_{\text {with }}$ an In content higher than $50 \%$ was achieved at elevated growth 
temperatures. The leveling off of the hole concentrations beyond an In content of $30 \%$ was correlated with the likely vanishing activation energy of $\mathrm{Mg}$ in $\mathrm{InGaN}$ at such a composition.

\section{Acknowledgements}

This work was funded by the NSC, Taiwan, R.O.C. We thank A. P. Chiu, Y. H. Hong, F. C. Lin, Y. Y. Wei, C. L. Chen, and C. Y. Cheng for useful discussion and for assisting us in our experiments.

1) See, for a review, K. S. A. Butcher and T. L. Tansley: Superlattices Microstruct. 38 (2005) 1.

2) See, for a review, A. G. Bhuiyan, A. Hashimoto, and A. Yamamoto: J. Appl. Phys. 94 (2003) 2779, and references therein.

3) S. K. Lin, K. T. Wu, C. P. Huang, C.-T. Liang, Y. H. Chang, Y. F. Chen, P. H. Chang, N. C. Chen, C. A. Chang, H. C. Peng, C. F. Shih, K. S. Liu, and T. Y. Lin: J. Appl. Phys. 97 (2005) 046101.
4) K. Kumakura, T. Makimoto, and N. Kobayashi: J. Appl. Phys. 93 (2003) 3370.

5) P.-C. Chen, C.-H. Chen, S.-J. Chang, Y.-K. Su, P.-C. Chang, and B.-R. Huang: Thin Solid Films 498 (2006) 113.

6) N. Yoshimoto, T. Matsuoka, T. Sasaki, and A. Katsui: Appl. Phys. Lett. 59 (1991) 2251.

7) J. Wu, W. Walukiewics, K. M. Yu, J. W. Ager III, E. E. Haller, H. Lu, W. J. Schaff, Y. Saito, and Y. Nanishi: Appl. Phys. Lett. 80 (2002) 3967.

8) T. Inushima, V. V. Mmutin, V. A. Vewkshin, S. V. Ivanov, T. Sakon, M. Motokawa, and S. Ohoya: J. Cryst. Growth 227-228 (2001) 481.

9) A. Yamamoto, T. Tanaka, K. Koide, and A. Hashimoto: Phys. Status Solidi A 194 (2002) 510.

10) C.-A. Chang, C.-F. Shih, N.-C. Chen, T. Y. Lin, and K.-S. Liu: Appl. Phys. Lett. 85 (2004) 6131.

11) T.-C. P. Chen, C. Thomidis, J. Abell, W. Li, and T. D. Moustakas: J. Cryst. Growth 288 (2006) 254.

12) C.-L. Wu, C.-H. Shen, H.-Y. Chen, S.-J. Tsai, H.-W. Lin, H.-M. Lee, S. Gwo, T.-F. Chuang, H.-S. Chang, and T. M. Hsu: J. Cryst. Growth 288 (2006) 247.

13) T. Matsuoka, H. Okamoto, M. Nakao, H. Harima, and E. Kurimoto: Appl. Phys. Lett. 81 (2002) 1246. 